\title{
Effect of ethanol on rat liver
}

\section{4.* The influence of vitamins, electrolytes and amino acids on the structure and function of mitochondria from rats receiving ethanol}

\author{
By K.-H. KIESSLING AND L. PILSTRÖM \\ Department of Cell Physiology, the Psychiatric Clinic, \\ St Göran's Hospital, Stockholm, Sweden \\ (Received 25 August I966-Accepted 16 Fanuary 1967 )
}

\begin{abstract}
I. Feeding rats with a I5\% ethanol solution for several weeks caused structural and functional changes in their liver mitochondria, although their intake of solid food was about the same as that of the controls.

2. Attempts were made to counteract these effects of ethanol by increasing the intake of amino acids, vitamins, lipotropic compounds and electrolytes beyond that which is adequate when water is the drinking fluid.

3. An increased intake of nicotinic acid, together with aqueous ethanol, caused a further enlargement of the mitochondria above that obtained with ethanol solution alone. The diluted matrix observed with the ethanol and nicotinic acid treatment suggested that water imbibition by the mitochondria caused this further enlargement.

4. In rats receiving ethanol fortified with magnesium sulphate and lipotropic compounds (choline, methionine) there was a further increase in mitochondrial size, as compared with those receiving ethanol alone. The matrix was, however, of the same density as in the mitochondria from the rats receiving ethanol alone. The oxidation rate of pyruvate and succinate was unchanged, but $\alpha$-glycerophosphate and $\beta$-hydroxybutyrate were oxidized at a higher rate than in mitochondria from rats drinking ethanol or water.

5. When the ethanol solution was supplemented with amino acids (casein hydrolysate), vitamins and electrolytes, the mitochondrial enlargement after 120 days of treatment was less than with ethanol alone and was completely absent after 300 days. The oxidation rate of pyruvate and succinate was, however, not fully restored to normal.
\end{abstract}

Cirrhosis includes structural and functional disorders of the liver. Intrahepatic venous shunts also deprive the body of the function of the liver, even though the liver cells are intact, thus producing circulatory hepatic insufficiency (Popper \& Zak, 1958). At present, although not fully proved, it is highly likely that cirrhosis in alcoholics develops through a stage of steatosis (Popper, I96r; Popper \& Zak, 1958). To what extent unbalanced nutrition is a factor in the hepatic steatosis of alcoholics is controversial. Most instances of clinically significant hepatic steatosis in alcoholics are reported to disappear rapidly if a diet adequate in protein is given (Kark, I960).

The results of Lieber, Jones \& DeCarli (1965), on the other hand, strongly support the possibility that ethanol itself is the cause of steatosis.

In rats we have observed hepatic steatosis as a consequence of acute intoxication with large doses of ethanol (Kiessling \& Pilström, I966, unpublished results). Prolonged treatment ( 12 months or longer) with a drinking fluid containing $\mathrm{I} 5-25 \%(\mathrm{v} / \mathrm{v})$ ethanol does not, however, produce obvious fat infiltration visible in the light or electron microscope; we have also not observed any marked signs of cirrhosis. In spite

* Paper no. 3: Acta chem. scand. (1966), 20, 2751. 
of this, obvious subcellular structural and functional changes, especially in the mitochondria, can be observed (Kiessling \& Tilander, 1961; Kiessling \& Tobé, 1964; Kiessling \& Pilström, г966a,b). These are manifested as enlargement of the mitochondria, disorganization and shortening of the cristae, and sometimes distortion of the mitochondria. No deviation in respect of mitochondrial lipid composition could be found (Lundquist, Kiessling \& Pilström 1966), although a slight change in the fatty acids has been reported (Scheig, Alexander \& Klatskin, I966), similar to that observed in deficiency of the essential fatty acids (Biran, Bartley, Carter \& Renshaw, 1965 ).

These mitochondrial changes arise even when the calorie intake in the form of ethanol amounts to only $25 \%$ of the total intake. No corresponding changes were observed in animals consuming the same amount of solid food and drinking a sucrose solution isocaloric with the ethanol. Similar structural changes have been observed in chronic alcoholics (Kiessling, Lindgren, Strandberg \& Tobé, 1964; Svoboda \& Manning, 1964), in whom a positive correlation has been found between the number of enlarged liver mitochondria and the degree of ethanol abuse (Kiessling, Pilström, Strandberg \& Lindgren, 1965).

As these mitochondrial changes in the rat are not mediated by a steatosis visible in the light or electron microscope, it is impossible to decide their aetiology from our present knowledge of the part played by ethanol and by nutritional factors in the development of steatosis. This investigation was an attempt to suppress the mitochondrial changes following long-term feeding of ethanol to the animals, by increasing their intake of certain nutritional compounds above the level which is adequate when water alone is the drinking fluid.

The supplements were given in the drinking fluid as single compounds (nicotinic acid), a mixture of a few chemicals (magnesium salt, choline and methionine) or as a combination of several nutritional factors (vitamins, electrolytes and amino acids).

\section{EXPERIMENTAL}

\section{Animals and treatments}

Wistar rats from this laboratory's stock were used. The males of each litter were divided into three groups: one to receive a $15 \%(\mathrm{v} / \mathrm{v})$ ethanol solution, one ethanol fortified with special compounds and one water fortified with the same compounds and a sucrose solution isocaloric with the ethanol consumed by the ethanol-drinking rats. The animals were kept in separate cages and had free access to adequate solid food. This food was a standard diet which has been used in our animal breeding for several years without giving any signs of deficiencies. The composition was: maize I3 $\%$, barley $24.5 \%$, oats $10 \%$, wheat feed flour $10 \%$, wheat germ $2 \%$, linseed oilcake meal $7 \%$, feeding bone flour $\mathrm{r} \cdot 25 \%$, meat and bone meal $2.5 \%$, cod-liver oil $0.5 \%$, wheat bran $10 \%$, lucerne meal $2 \%$, dried whole milk $15 \%$, brewer's dried yeast $2 \%$, iodized salt $(\mathrm{NaCl}$ containing $0.005 \%$ iodide $/ \mathrm{kg}$ ) $0.25 \%$. Approximately $35 \%$ of the food was protein, $3 \%$ lipids, $50 \%$ carbohydrates, $\mathbf{r} \cdot 2 \%$ calcium, $0.9 \%$ phosphorus and $10 \%$ water. 
The animals were weighed once a week and their intakes of solid food and of drinking fluid were measured during a Io-day period every 2 nd month. The amount of solid food consumed was the same for the animals given ethanol alone, ethanol plus nicotinic acid and ethanol plus choline and methionine $(53 \mathrm{~g}$ per $\mathrm{kg}$ per day at the age of 6 months) and a little lower ( $50 \mathrm{~g}$ per $\mathrm{kg}$ ) for those receiving ethanol or water, together with amino acids, vitamins and electrolytes. No differences were found in the amount of fluid consumed per day between the experimental groups $(74-76 \mathrm{ml}$ per kg at the age of 6 months).

When ethanol was added to the daily fluid to give a $15 \%(\mathrm{v} / \mathrm{v})$ solution, $25 \%$ of the total calorie intake came from ethanol. Long-term feeding with this concentration of ethanol caused a moderate growth retardation ( $23 \%$ after 60 days, $21 \%$ after 2 I 0 days). Increasing the calorie intake in the form of ethanol to $35 \%$ caused a severe inhibition of growth and often led to death.

Nicotinic acid. The drinking fluids, either water or the $15 \%(\mathrm{v} / \mathrm{v})$ ethanol solution, were made $60 \mathrm{~mm}$ with respect to nicotinic acid. The fluids were neutralized by the addition of solid $\mathrm{Na}_{2} \mathrm{CO}_{3}$. With a daily fluid intake of about $27 \mathrm{ml}$, the rats received $200 \mathrm{mg}$ of added nicotinic acid per day.

Magnesium, choline and methionine. $\mathrm{MgSO}_{4}$, choline and DL-methionine were dissolved in the drinking fluids. The final concentrations were: $\mathrm{MgSO}_{4} 8 \mathrm{~mm}$, choline $3.5 \mathrm{mM}$, and methionine $27 \mathrm{mM}$. The compounds were readily soluble in both fluids.

Amino acids, vitamins and electrolytes. The mixture of amino acids was an enzymic hydrolysate of casein (manufactured by Vitrum, Stockholm). From this, $25 \mathrm{~g}$ were added per 1 . of the drinking fluids. As the hydrolysate was not completely soluble, the fluids were slightly turbid. The drinking fluids also contained inorganic compounds in the final concentrations: $\mathrm{NaCl} 43 \mathrm{mM}, \mathrm{KCl} 34 \mathrm{mM}, \mathrm{CaCl}_{2}$ I I $\mathrm{mm}$ and $\mathrm{MgCl}_{2}$ I 3 mM. The $\mathrm{pH}$ of the fluids was adjusted to $7 \cdot 0$ by adding small amounts of a $\mathrm{O} \cdot \mathrm{I} \mathrm{M}-$ $\mathrm{KOH}$ solution. The vitamins were administered in solid form as chewing tablets. The mean daily intake was: retinol 1250 i.u., thiamine $0.75 \mathrm{mg}$, riboflavine $0.75 \mathrm{mg}$, pyridoxine chloride $0.5 \mathrm{mg}$, nicotinamide $8 \mathrm{mg}$, calcium pantothenate $2 \mathrm{mg}$, ascorbic acid $5 \circ \mathrm{mg}$, cholecalciferol $\mathrm{I}_{2} 5 \mathrm{i}$.u. and $\alpha$-tocopheryl acetate $2.5 \mathrm{mg}$.

\section{Electron microscopy}

Animals were anaesthetized with ether. Small pieces of peripheral parts of a liver lobe (the same parts in both the experimental and the control animals) were cut out and put into ice-cold $2 \%$ osmium-tetroxide solution for $2 \mathrm{~h}$, dehydrated in ethanol, embedded in Epon and sliced with an ultramicrotome from LKB Produkter AB. The sections were taken up directly on naked grids and examined in an Akashi Tronscope Model TRS-50 E $\mathrm{I}$ or a Zeiss EM 9 electron microscope. The periportal connective tissue was avoided. In order to eliminate experimental errors, the same magnification was always used in the microscope. Several parts of each sample were examined.

From electron-microscopic pictures we sought to determine the size of the mitochondrial profiles by measuring the length and the breadth of each mitochondrion and calculating the area by applying the formula for an ellipse. At least 300 mitochondria from each sample were measured. 
A necessary prerequisite when comparing the sizes of mitochondria from the ethanol-treated animals with those of mitochondria from the controls by means of electron microscopy is that the photographs be taken completely at random. There must be no possibility of selection of the photographs which would support a particular hypothesis. In order to avoid this, the person taking the micrographs did not know from which animal the sample originated. Secondly, the areas were chosen at such a low enlargement $(\times 2000)$ that there was no possibility of deciding whether the mitochondria were bigger than normal. The desired enlargement $(\times 3000)$ was then made.

On the micrographs (final enlargement $\times 9000$ ) every mitochondrial profile was measured, regardless of size.

Each animal was represented by six grids, each composed of serial cuttings from different levels of the liver piece.

\section{Mitochondrial respiration}

The investigation was initially planned to be only an electron-micrographic study of the mitochondrial changes. In the experiments with choline and methionine and with a mixture of amino acids, vitamins and electrolytes the study was extended to include the mitochondrial respiration. The methods were as follows. The animals were decapitated and liver mitochondria were prepared for manometric studies, according to the method of Ernster \& Löw (1955). Finally the mitochondria were suspended in isotonic sucrose, so that $\mathrm{I} \mathrm{ml}$ contained mitochondria from $300 \mathrm{mg}$ of liver. The respiratory rates with four substrates (pyruvate, succinate, $\alpha$-glycerophosphate and $\beta$-hydroxybutyrate) were determined manometrically with the same additions as described previously (Kiessling \& Tilander, 1963 ). The temperature was $30^{\circ}$ and the gas phase was air. Proteins were determined according to Cleland \& Slater (1953) by a colorimetric method depending on the protein biuret reaction.

\section{RESULTS}

Nicotinic acid. When nicotinic acid was added to the daily fluid the rats had already been treated with ethanol for 280 days and the profiles of the liver mitochondria were on an average $35 \%$ larger than those of the controls (Fig. I). The addition of nicotinic acid did not counteract this enlargement. On the contrary, it brought about a further enlargement of the mitochondria by nearly $60 \%$. A much lesser enlargement was also observed in the controls, which were kept on water containing nicotinic acid. The further enlargement caused by nicotinic acid was different from that caused by ethanol alone. With ethanol alone the matrix of the enlarged mitochondria was of the same density as that of the controls. The enlarged mitochondria observed when nicotinic acid was given together with ethanol contained a matrix much less electron-opaque than normal, indicating a swelling caused by water imbibition.

Continued intake of ethanol and added nicotinic acid for a further $15^{\circ}$ days brought the mitochondrial size back to that found with ethanol alone.

Magnesium, choline and methionine. In one set of experiments the ethanol solution 


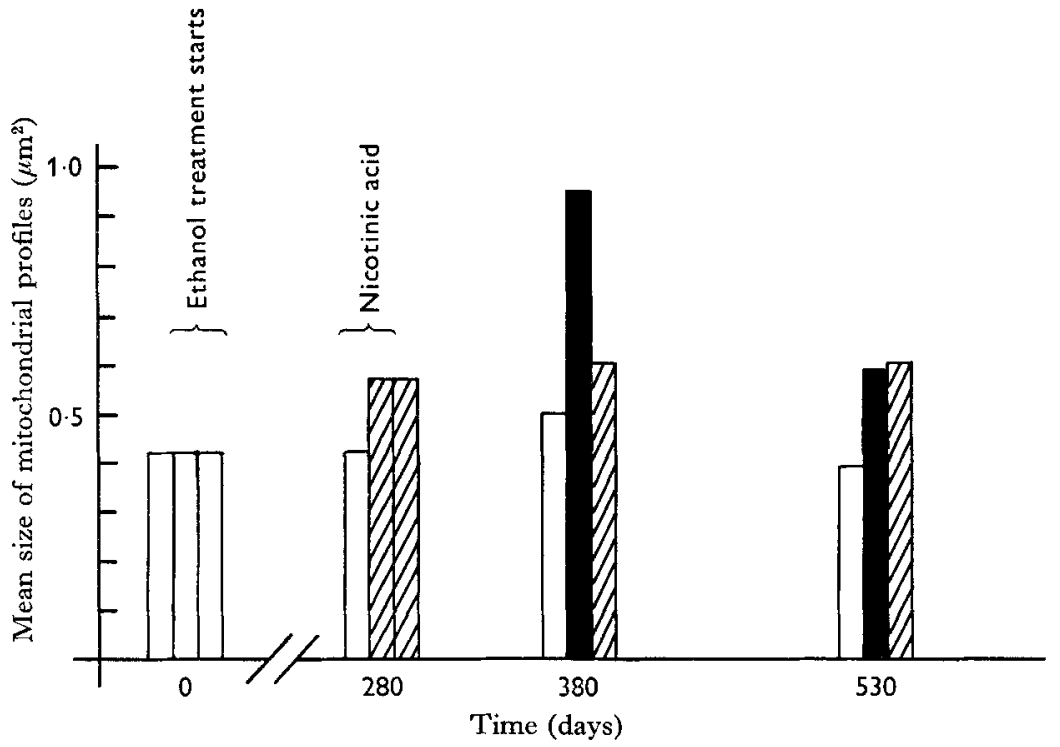

Fig. 1. The effect on the mitochondrial size of giving rats nicotinic acid, together with ethanol. Each column represents the mean value for at least izoo mitochondria from four animals. At the age of 30 days (indicated by zero on the abscissa) two groups of rats were given a $15 \%$ ethanol solution as the only drinking fluid and a third group was given water. After 280 days the drinking fluid of one of the ethanol groups and that of the water group were fortified with nicotinic acid for another 250 days. The third group, as before, received ethanol only, $\square$, o-280 days water, then water + nicotinic acid; $\mathbf{\square}$, ethanol + nicotinic acid; $叉$, ethanol.

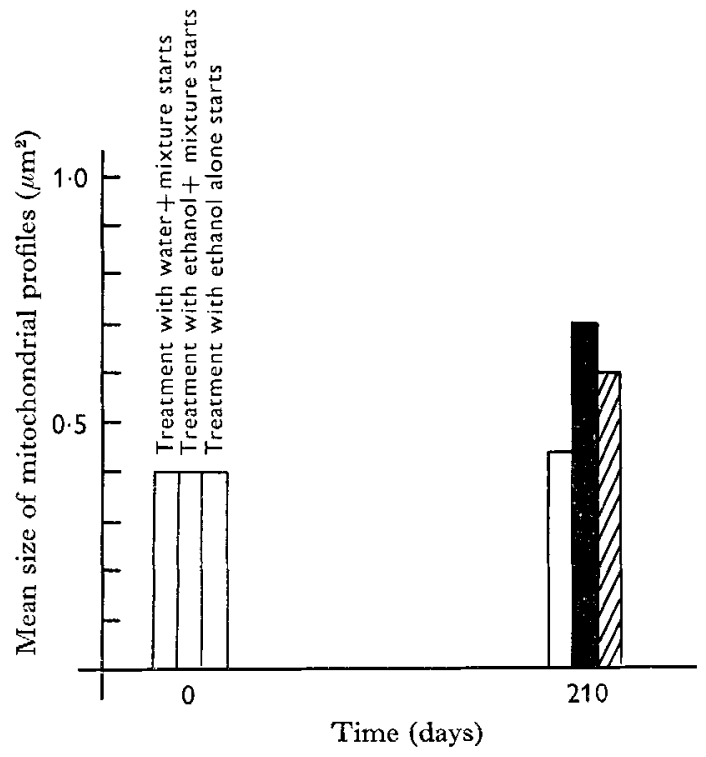

Fig. 2. The effect of magnesium, choline and methionine on the enlargement of liver mitochondria in rats caused by drinking ethanol. Each column represents the mean value of at least 1200 mitochondria from four animals. At the age of 30 days (indicated by zero on the abscissa) the first group of rats was given drinking water fortified with magnesium, choline and methionine (see p. 549), the second group a I $5 \%$ ethanol solution + mixture and the third group a $15 \%$ ethanol solution alone. This treatment was continued for 2 ro days. $\square$, water + mixture; $\mathbf{G}$, ethanol + mixture; $\square$, ethanol. 
was fortified with $\mathrm{MgSO}_{4}$, choline and methionine for 7 months and Fig. 2 shows the effect of this solution on the size of the liver mitochondria. Instead of counteracting the enlargement of the mitochondria caused by ethanol alone, the additions themselves gave rise to an enlargement. The deviations on mitochondrial shape and cristae organization were the same in both ethanol-treated groups and agreed with those previously described (Kiessling \& Tobé, I964; Kiessling \& Pilström, I966b). No sign of a diluted matrix resembling that described above, with added nicotinic acid, could be observed in either group receiving ethanol. This finding indicates that swelling of the matrix as a result of water imbibition was not a contributory factor to the additional enlargement observed in the group of rats receiving ethanol and the mixture.

The capacity of the liver mitochondria to oxidize pyruvate and succinate was about equally reduced in the two experimental groups; that is, in those given ethanol alone and in those given ethanol fortified with the $\mathrm{MgSO}_{4}$-choline-methionine mixture (Table I). Thus, the further increase in size caused by administering this mixture, together with ethanol, did not decrease the oxidation rate further.

Table I. Effect of giving rats a mixture of magnesium, choline and methionine on the reduction caused by ethanol in the mitochondrial oxidation rate of pyruvate and succinate

(Mean values with their standard errors for four experiments, determined after the animals had been treated for 210 days with the mixture)

Drinking fluid

Water + mixture

Ethanol + mixture

Ethanol

\begin{tabular}{|c|c|c|c|c|}
\hline \multirow[b]{2}{*}{ Drinking fluid } & \multicolumn{4}{|c|}{ Oxygen consumption ( $\mu$-atoms/10 mg protein $\mathrm{h}$ ) } \\
\hline & Pyruvate & Succinate & $\begin{array}{l}\alpha \text {-glycero- } \\
\text { phosphate }\end{array}$ & $\begin{array}{c}\beta \text {-hydroxy- } \\
\text { butyrate }\end{array}$ \\
\hline Water + mixture & $4 I \cdot 2 \pm 0 \cdot 5$ & $49^{\circ} 4 \pm 0.7$ & $16 \cdot 0 \pm 0.6$ & $23 \cdot 0 \pm 1 \cdot 4$ \\
\hline Ethanol + mixture & $3 r \cdot 0 \pm 0.8$ & $33.0 \pm 0.9$ & $22 \cdot 2 \pm 0.8$ & $28 \cdot 2 \pm 0 \cdot 7$ \\
\hline Ethanol & $30.4 \pm 0.9$ & $32 \cdot 2 \pm 0.9$ & $16.3 \pm 0.6$ & $22 \cdot 1 \pm 0 \cdot 7$ \\
\hline
\end{tabular}

With $\alpha$-glycerophosphate and $\beta$-hydroxybutyrate the oxidation rate was increased in mitochondria from rats drinking ethanol fortified with $\mathrm{MgSO}_{4}$-choline-methionine compared with those drinking water or ethanol alone (35\% and $22 \%$ respectively).

Amino acids, vitamins and electrolytes. In experiments similar to those described above, a mixture of amino acids, vitamins and electrolytes was added to the drinking fluids. From Fig. 3 it may be concluded that at the beginning the mitochondrial enlargement accompanying prolonged ethanol consumption was retarded, although not prevented, when ethanol was supplemented with the mixture. Prolonged addition of ethanol and the mixture restored the mitochondrial size to that of the controls. It must be mentioned that a few elongated or vacuolized mitochondria were still present in these livers and were slightly more frequent than in the controls.

The mitochondria from rats receiving ethanol and the mixture still oxidized pyruvate and succinate at a lower rate than the controls, although more rapidly than mitochondria from animals receiving ethanol alone (Table 2).

The body-weight of the rats receiving ethanol or ethanol and the mixture was lower than that of the controls ( 23 and $21 \%$ respectively). 
Table 2. Effect of giving rats a mixture of amino acids, vitamins and electrolytes on the reduction caused by ethanol of the mitochondrial oxidation rate of pyruvate and succinate

(Mean values with their standard errors for four experiments, determined after the animals had been treated for 300 days with the mixture)

\begin{tabular}{|c|c|c|c|c|}
\hline \multirow[b]{2}{*}{ Drinking fluid } & \multicolumn{4}{|c|}{ Oxygen consumption ( $\mu$-atoms/Io mg protein $\mathrm{h}$ ) } \\
\hline & Pyruvate & Succinate & $\begin{array}{l}\alpha \text {-glycero- } \\
\text { phosphate }\end{array}$ & $\begin{array}{c}\beta \text {-hydroxy- } \\
\text { butyrate }\end{array}$ \\
\hline Water + mixture & $4 I \cdot 0 \pm 2 \cdot 8$ & $53 \cdot 7 \pm 2 \cdot 6$ & $14.0 \pm 0.7$ & $22 \cdot 2 \pm 0 \cdot 9$ \\
\hline Ethanol + mixture & $34 \cdot 8 \pm 0 \cdot 6$ & $43 \cdot 5 \pm 2 \cdot 5$ & $13 \cdot 8 \pm 1.0$ & $23.7 \pm 0.6$ \\
\hline Ethanol & $30.4 \pm 0.9$ & $32 \cdot 2 \pm 0.9$ & $16.3 \pm 0.6$ & $22 \cdot 0 \pm 0.7$ \\
\hline
\end{tabular}

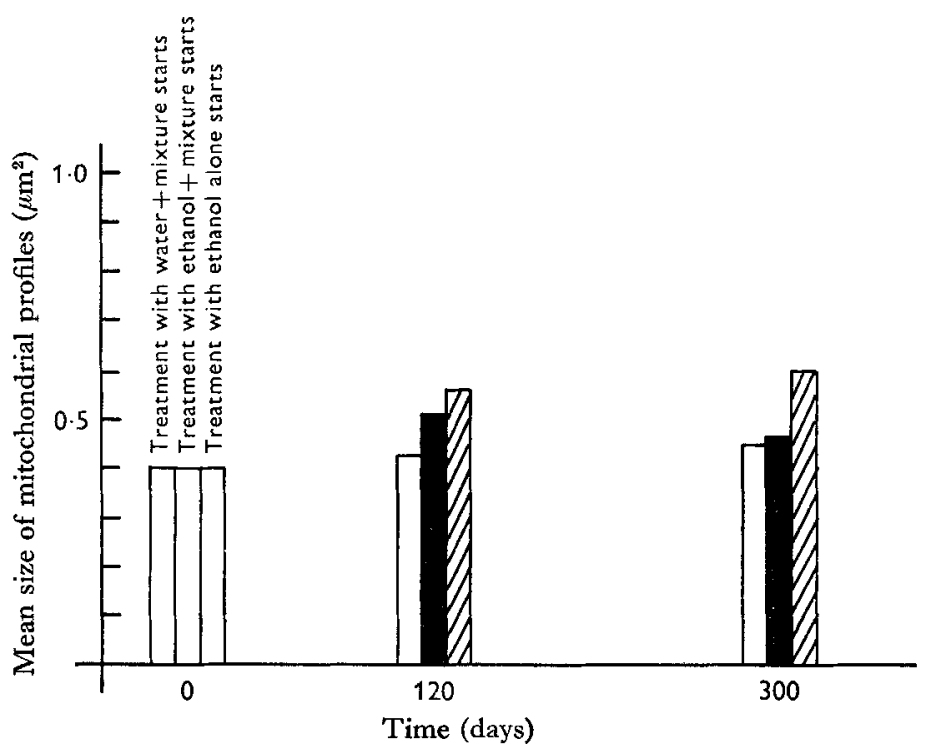

Fig. 3. The effect of amino acids, vitamins and electrolytes on the enlargement of liver mitochondria in rats caused by drinking ethanol. Each column represents the mean value of at least 1200 mitochondria from four animals. At the age of 30 days (indicated by zero on the abscissa) the first group was given drinking water fortified with amino acids, vitamins and electrolytes (see p. 549), the second group a $\mathrm{r}_{5} \%$ ethanol solution + mixture and the third group a $15 \%$ ethanol solution alone. This treatment was continued for 300 days. $\square$, water + mixture; $\square$, ethanol + mixture; $\square$, ethanol.

\section{DISCUSSION}

Nicotinic acid. Ethanol was supplemented with nicotinic acid for several reasons. In the first place, it is known that the liver content of total NAD is low after prolonged ethanol treatment (Mirone, 1966), that nicotinic acid is a precursor of NAD and is excreted as methylnicotinamide in higher amounts than normal in rats receiving ethanol (Erkki, Konttinen \& Suomalainen, 1963) and that addition of NAD to liver mitochondria from rats receiving ethanol slightly restores the decreased oxidation rate of pyruvate (Kiessling \& Tilander, I96I).

Nicotinic acid also counteracts the release of fatty acids from the adipose tissue (Carlson \& Orö, 1962) and consequently reduces the supply of free fatty acids to the liver. Free fatty acids are known to cause an enlargement of liver mitochondria, 
together with a reduced oxidation rate and uncoupled oxidative phosphorylation (Lehninger \& Remmert, 1959). The increased concentration of free fatty acids in serum in connexion with ethanol supply is considered to depend at least partly, on an ethanol-stimulated release (Isselbacher \& Greenberger, I964a,b) and may therefore be counteracted by nicotinic acid.

In our experiments (Fig. I) the effect of nicotinic acid was rather unexpected. Instead of counteracting the ethanol-induced enlargement of liver mitochondria, it caused a further increase in their size. In these mitochondria the matrix was less electron-opaque than in enlarged mitochondria from rats which received ethanol without added nicotinic acid. Prolonged administration of ethanol and nicotinic acid caused a return of the mitochondrial size and the density of the matrix to those of the animals receiving ethanol alone (Fig. I). In the controls this effect of nicotinic acid was not so pronounced, indicating that the mechanism regulating water imbibition by the matrix is more easily disturbed in liver mitochondria from rats receiving ethanol than in those from controls.

Magnesium, choline and methionine. The need for magnesium and lipotropic compounds rises during long-term feeding with ethanol. Thus, in chronic alcoholism a severe hypomagnesemia often occurs (Heaton, Pyrah, Beresford, Bryson \& Martin, I962; Martin, McCuskey \& Tupikova, I959), mainly due to an increased urinary loss of magnesium (Heaton et al. 1962; Martin et al. 1959; Kalbfleisch, Lindeman \& Smith, I96I; McCollister, Flink \& Doe, I960; McCollister, Flink \& Lewis, 1963).

Rats fed on a high-fat, low-protein diet develop steatosis and even cirrhosis (Lowry, Ashburn, Daft \& Sebrell, 1942), and in man severe protein malnutrition is accompanied by steatosis and subsequent fibrosis (Waterlow, 1955). Similar effects are observed in rats fed on a hypercaloric diet lacking methionine and choline. The same diet supplemented with these lipotropic substances did not induce steatosis (Best, Hartroft, Lucas \& Ridout, 1949). In animal experiments it has been established that prolonged ethanol consumption leads to an increased metabolic requirement for choline which is not simply the result of a poor dietary intake (Klatskin \& Kreh1, 1954; Klatskin, Krehl \& Conn, 1954).

In our experiments we added a mixture of magnesium sulphate, choline and methionine to the drinking fluid. From Fig. 2 and Table $\mathrm{I}$ it is apparent that the mitochondrial changes due to the addition of ethanol were not reversed by these compounds. On the contrary, they brought about a further brief increase in size and an increased capacity of the mitochondria to oxidize $\alpha$-glycerophosphate and $\beta$-hydroxybutyrate, indicating that neither a magnesium deficiency nor an increased requirement for lipotropic compounds caused the mitochondrial changes in the rats receiving ethanol.

Amino acids, vitamins and electrolytes. Human beings who drink excessive amounts of ethanol have no appetite for solid food. Thus, it is not uncommon to observe alcoholics who do not eat anything for weeks. The consequences are protein malnutrition inducing hypoproteinemia, œdema and cirrhosis, and vitamin deficiencies leading to polyneuropathies and pellagra. Ethanol consumption also depletes the body of certain electrolytes (McCollister et al. 1960; Martin et al. 1959). 
In most instances an insufficient supply of these nutritional components is not, however, the sole explanation. Possible mechanisms suggested, besides poor intake, include poor gastro-intestinal absorption and an accelerated urinary excretion. Thus, several of the members of the vitamin- $B$ complex are excreted in higher amounts during ethanol intake (Erkki et al. 1963; Butler \& Sarret, 1948). The liver contents of thiamine and its coenzyme form, thiamine pyrophosphate, decrease (Kiessling \& Tilander, 1960). Vitamin A also decreases in the liver of rats (Baumann, Foster \& Moore, 1942).

Svoboda \& Higginson (1964) have investigated ultrastructural changes in rat liver produced by protein deficiency. The main mitochondrial changes were a decreased number of mitochondria, cavitation of their matrices and dissolution of their membranes. Many mitochondria contained inclusions consisting of stratified fibrils with a beaded or helical configuration. Many mitochondria seem to have been larger than normal.

Only in the last respect do these mitochondrial changes agree with those observed by us in rat liver after prolonged intake of ethanol by the animals. No reduction in the number of mitochondria was observed in rats receiving ethanol (Kiessling \& Pilström, I $966 b$ ), nor did we find dissolution of the membranes or inclusions similar to those described by Svoboda \& Higginson (I964). Extending the ethanol administration to I 5 months or increasing the ethanol concentration does not cause the same mitochondrial changes as in protein deficiency. This strongly indicates that the structural changes observed by us were not caused by a protein deficiency brought about by ethanol replacing part of the protein in the food. Besides, the ethanol-drinking rats consumed the same amount of solid food per day as the controls, which received isocaloric amounts of sucrose solution and which showed no mitochondrial deviations.

The addition of amino acids (casein hydrolysate), vitamins and electrolytes to the ethanol counteracted, nevertheless, the effect of the ethanol on the mitochondrial size. This retardation was only slightly visible after 120 days but was complete at 300 days (Fig. 3). Which component(s) is responsible for this effect is impossible to decide from the present investigation. But certain substances such as magnesium, nicotinic acid, choline and methionine can be excluded. Further studies may reveal whether the active factor is a single substance or several compounds giving a combined effect.

Rather unexpectedly, the oxidation rate of pyruvate and succinate was only partly restored after the mitochondrial shape had returned to normal (Table 2). Thus, overdosage with one or more, as yet unknown, nutritional compounds counteracts changes in mitochondrial shape and size but only partly counteracts functional changes. This suggests that structural and functional changes in liver mitochondria following prolonged ethanol intake are not necessaily connected.

This work is part of investigations made possible by grants from the Swedish Medical Science Research Council and from Nya Systemaktiebolaget, Stockholm, Sweden.

We are indebted to Professor C.-H. Alström for placing the necessary facilities at 
our disposal; to Professors P.-E. Lindahl and C. G. Bernhard for giving us the opportunity to use the electron microscopes; to Miss Maj-Britt Jansson, Miss Helga Möbius and Miss Ann-Sofie Wallin for skilful technical assistance.

\section{REFERENCES}

Baumann, C. A., Foster, E. G. \& Moore, P. R. (1942). F. biol. Chem. 142, 597.

Best, C. H., Hartroft, W. S., Lucas, C. C. \& Ridout, J. H. (1949). Br. med. F. ii, roor.

Biran, L. A., Bartley, W., Carter, C. W. \& Renshaw, A. (I965). Biochem. F. 94, 247.

Butler, R. F. \& Sarret, H. D. (1948). F. Nutr. 35, 535.

Carlson, L. A. \& Orö, L. (1962). Acta med. scand. I72, 641.

Cleland, K. W. \& Slater, E. C. (1953). Biochem. F. 53, 547.

Erkki, O., Konttinen, K. \& Suomalainen, H. (I963). Acta physiol. scand. 59, suppl. 213, p. I I9.

Ernster, L. \& Löw, H. (1955). Expl Cell Res. suppl. 3, p. 133.

Heaton, F. W., Pyrah, L. N., Beresford, C. C., Bryson, R. W. \& Martin, D. F. (ı962). Lancet ii, 802.

Isselbacher, K. J. \& Greenberger, N. J. (1964a). New Engl. $\mathcal{F}$. Med. 270, 35 I.

Isselbacher, K. J. \& Greenberger, N. J. (1964b). New Engl. $\mathcal{~ . ~ M e d . ~ 2 7 0 , ~} 402$.

Kalbfleisch, J. M., Lindeman, R. D. \& Smith, W. O. (1961). F. Lab. clin. Med. 58, 833.

Kark, R. M. (r960). Gastroenterology 39, 643 .

Kiessling, K.-H., Lindgren, L., Strandberg, B. \& Tobé, U. (1964). Acta med. scand. 176, 595.

Kiessling, K.-H. \& Pilström, L. (I966a). Q. Il Stud. Alcohol. 27, i 89.

Kiessling, K.-H. \& Pilström, L. (1966 b). Acta pharmac. tox. 24, 989.

Kiessling, K.-H., Pilström, L., Strandberg, B. \& Lindgren, L. (1965). Acta med. scand. 178, 533.

Kiessling, K.-H. \& Tilander, K. (1960). Expl Cell Res. 19, 628.

Kiessling, K.-H. \& Tilander, K. (196I). Q. Fl Stud. Alcohol. 22, 535.

Kiessling, K.-H. \& Tilander, K. (1963). Expl Cell Res. 30, 476.

Kiessling, K.-H. \& Tobé, U. (1964). Expl Cell Res. 33, 350.

Klatskin, G. \& Krehl, W. A. (r954). F. exp. Med. roo, 6r 5 .

Klatskin, G., Krehl, W. A. \& Conn, H. O. (1954). F. exp. Med. roo, 605.

Lehninger, A. L. \& Remmert, L. F. (I959). F. biol. Chem. 234, 2459.

Lieber, C. S., Jones, D. P. \& DeCarli, L. M. (1965). F. clin. Invest. 44, 1009.

Lowry, J. V., Ashburn, L. L., Daft, F. S. \& Sebrell, W. H. (1942). Q. Il Stud. Alcohol. 3, 168.

Lundquist, C.-G., Kiessling, K.-H. \& Pilström, L. (I 966). Acta chem. scand. 20, 275 I.

McCollister, R. J., Flink, E. B. \& Doe, R. P. (1960). F. Lab. clin. Med. 55, 98.

McCollister, R. J., Flink, E. B. \& Lewis, M. D. (1963). Am. F. clin. Nutr. 12, 41 5.

Martin, H. E., McCuskey, C. M. Jr \& Tupikova, N. (r959). Am. F. clin. Nutr. 7, rgr.

Mirone, I. (1966). Life Sciences 5, 317.

Popper, H. (ro6r). Acta Hepato-splenol. 8, 279.

Popper, H. \& Zak, F. G. (1958). Am. F. Med. 24, 593.

Scheig, R., Alexander, N. M. \& Klatskin, G. (1966). F. Lipid Res. 7, 188.

Svoboda, D. J. \& Higginson, J. (1964). Am. F. Path. 45, 353.

Svoboda, D. J. \& Manning, R. T. (I964). Am. F. Path. 44, 645.

Waterlow, J. (editor) (1955). Protein Malnutrition: Proceedings of a Conference in Famaica, 1953. London and New York: Cambridge University Press. 